\title{
Limpeza com laser de excímeros de papéis e pergaminhos com lama
}

\author{
J.P. Duarte ${ }^{(*)}$ e P. Peças ${ }^{(*)}$
}

\begin{abstract}
Sumário A principal vantagem dos lasers de excímeros, no processamento de materiais, é a emissão de um feixe luminoso com comprimento de onda compreendido na região do ultravioleta, permitindo uma remoção do material com precisão muito elevada e excelente definição de bordos, ausência de zona térmicamente afectada e ausência de alterações da estrutura.

$\mathrm{Na}$ limpeza dos papéis e pergaminhos a lama é removida por quebra das ligações fisico-químicas entre a lama e o papel não se afectando a estrutura deste, assim como não se afectaram os pigmentos cromáticos existentes em algumas amostras.
\end{abstract}

Palavras chave: Limpeza com laser de excímeros. Restauro de papel e pergaminho.

\section{Excimer laser cleaning of mud stained paper and parchment}

\begin{abstract}
The main advantage of excimer lasers when processing materials, its the emission of a radiation with wavelength in the ultraviolet region. This characteristic allows an extremely accurate and very well defined shape of material removal as well as total absence of heat affected zone and alterations in the material structure.

In excimer laser paper and parchment cleaning, the mud is removed by breaking the physicalchemical bonding between this last one and the material to be cleaned not affecting neither its structure nor the chromatic pigment existing in some samples.
\end{abstract}

Keywords: Excimer laser cleaning. Paper and parchment restauration.

\section{INTRODUÇÃO}

Em Novembro de 1967 sobre a zona de Lisboa caiu uma tromba de água que resultou numa catástrofe, vitimando centenas de vidas humanas e destruindo bens materiais e culturais. As reservas do recém criado Museu Calouste Gulbenkian não foram poupadas. Desde essa altura se tentam recuperar obras em papel e pergaminho afectadas pelas águas, constituídas por manuscritos islâmicos, estampas japoneses, desenhos e gravuras ocidentais e manuscritos europeus. Os problemas de maior complexidade para os técnicos de restauro, residem na remoção das lamas que impregnam as fibras desses suportes e que cobrem zonas com texto e imagem.

Os tratamentos são necessariamente lentos, dadas as características das peças, utilizando para o efeito instrumentos de raspagem, abrasão ou solventes orgânicos, aquosos ou semi-aquosos.

(*) Instituto de Soldadura e Qualidade (Portugal).
Obtém-se resultados razoáveis com recurso a solventes, mas se o efeito de dissolução retira a grande maioria das partículas de lama, uma quantidade minima penetra ainda mais fundo nas fibras. A maioria das obras foi restaurada com todo o rigor, seguindo técnicas conhecidas e desenvolvidas por peritos, mas qualquer dos tratamentos representa, uma ligeira agressão na textura superficial quando são empregues agentes físicos de raspagem ou abrasão.

De forma a obter melhores resultados e uma menor agressão na textura dos documentos resolveu-se recorrer à tecnologia laser. A principal vantagem dos lasers de excímeros no processamento de materiais é a emissão de um feixe luminoso com comprimento de onda compreendido na região do ultravioleta, permitindo uma remoção do material com precisão muito elevada e excelente definição de bordos, ausência de zona térmicamente afectada e ausência de alterações da estrutura do material.

O laser de excímeros é um laser pulsado cujo meio activo é gasoso e emite radiação luminosa na 
região do ultra-violeta. Para cada tipo de mistura gasosa obtém-se um determinado comprimento de onda da radiação, sendo as misturas gasosas características ArF (193nm), KrF (248nm), XeCl $(308 \mathrm{~nm})$ e XeF $(351 \mathrm{~nm})$.

A grande maioria dos materiais absorve muito bem a radiação ultra-violeta o que provoca um bom acoplamento feixe-matéria. Para densidades de energia da mancha superiores a um dado valor limite, a interacção feixe-matéria dá-se por um processo fotoablativo. Por cada impulso laser ocorre a destruição das ligações químicas à superfície do material a ser processado, em profundidades que variam desde $0,1 \mathrm{~m}$ até algumas centenas de micrometro, valor este que depende do material, e está directamente ligado com o efeito de pele (skin effect) (1-3).

\section{EXPERIMENTAÇÃO}

Realizaram-se vários ensaios de limpeza em diferentes tipos papéis antigos, principalmente, papéis islâmicos, sendo o arranjo experimental utilizado o que se apresenta na figura 1. Testaramse diferentes tipos de lentes de focalização, lentes esféricas e lentes cilíndricas obtendo-se manchas focais circulares e lineares respectivamente. A remoção das partículas de lama em áreas extensas foi obtida através do varrimento da mancha focal sobre o material impregnado. A profundidade da

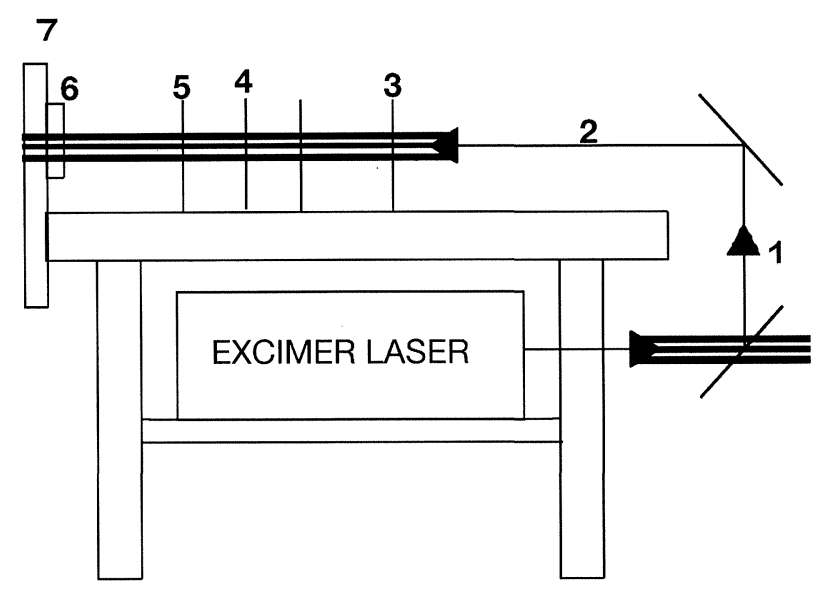

Fig. 1.- Arranjo experimental.
1. Espelhos reflectores a $45^{\circ}$
2. Feixe laser
3. Telescópio
4. Máscara
5. Lente de focalização
6. Amostra
7. Mesa XY

FIG. 1.- Experimental Set-up.
$1.45^{\circ}$ reflecting mirrors
2. Laser beam
3. Expanding system
4. Mask
5. Focusing lens
7. XY moving table
6. Sample

camada removida é dependente da velocidade de varrimento que por sua vez é directamente proporcional à frequência de repetição dos impulsos laser.

\section{RESULTADOS Y DISCUSSAO}

Depois de limpas, as diferentes amostras foram examinadas com um microscópio estereoscópio. Esta análise permitiu comparar a estrutura das amostras antes e depois de irradiadas. Observou-se que após irradiação com radiação ultra-violeta os materiais base, papéis e/ou pergaminho, não sofreram alterações, ou seja não existe quebra ou ruptura das fibras que constituem o material.

As figuras 2, 3 e 4 ilustram este resultado em amostras de papel de algodão forte e em papel islâmico. Na figura 2 é possível observar zonas sujas com lama, as zonas mais escuras. Após irradiação com o feixe laser estas zonas quase desaparecem e a estrutura base do material não é alterada.

Para que ocorra o processo fotoablativo na remoção das lamas são necessárias densidades de energia da ordem dos $1,0 \mathrm{~J} / \mathrm{cm}^{2}$. Das técnicas apresentadas, manchas focais circulares ou lineares, a que permite tempos de limpeza menores consiste na focalização em linha tendo sido ensaiado uma mancha focal com a área de $23 \times 0,10 \mathrm{~mm}^{2}$.

Em zonas em que a camada de lama atinge espessuras elevadas, é necessário uma operação prévia de remoção da lama por técnicas convencionais. Esta operação suplementar é devida à pequena penetração da radiação ultra-violeta. Após a remoção grosseira da lama, aplica-se a técnica desenvolvida para remoção superficial das lamas.

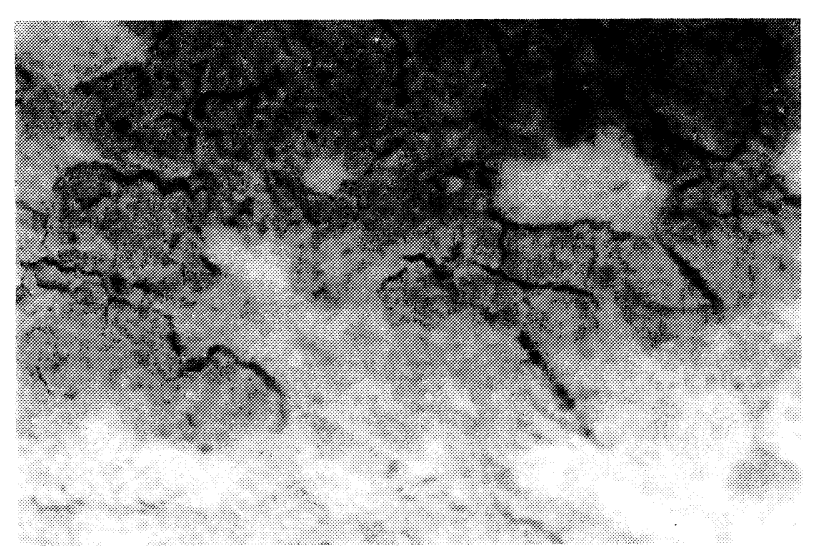

FIG. 2.- Manuscrito LA237 antes de limpeza (Ampliação:50X)

FIG. 2.- LA237 Manuscript before cleaning (Magnification: 50X) 


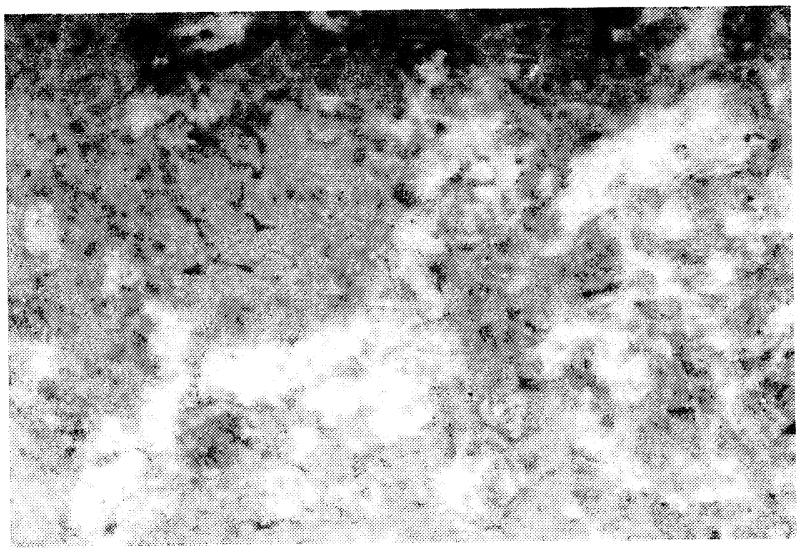

FIG. 3.- Manuscrito LA237 após limpeza (Ampliação: 50X)

FIG. 3.- LA237 Manuscript after cleaning (Magnification: 50X)

Por observação microscópica das amostras e comparação entre as fotografias das amostras antes e depois de irradiadas com a radiação ultra-violeta, pode-se concluir que com esta técnica de limpeza não se produzem alterações estruturais do material base, as fibras que constituem os papéis e os pergaminhos não são danificadas. O efeito da radiação ultravioleta absorvida pelo substracto é um factor crítico, já que influencia o estado de envelhecimento do documento tratado. A continuação de trabalhos vai incidir na optimização

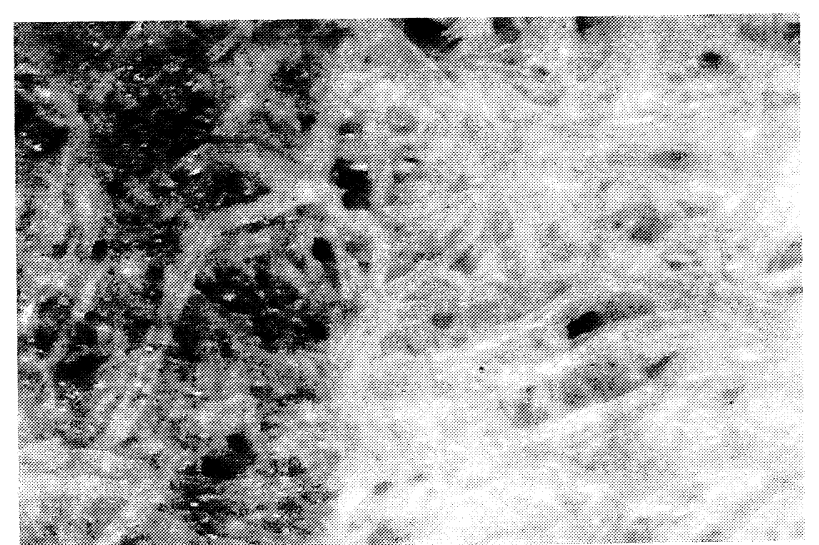

FIG. 4.- Manuscrito islâmico após limpeza (Ampliação:50X)

FIG. 4.- Islamic manuscript after cleaning (Magnification: 50X)

das taxas de remoção das lamas e na análise do estado de envelhecimento das zonas tratadas.

\section{REFERENCIAS}

(1) "Surface cleaning by UV laser radiation becomes economical", Lambda Highlights, 47,May 1995, 1-5.

(2) Miranda, R., Duarte, J. P.; "O laser de excímeros como ferramenta de marcação", Tecnologia e Qualidade, 9, Jan/Mar,1993, 38-40.

(3) Olsen, Flemming O. "Factos sobre: processamento de materiais a laser", AGA, 1992. 